\title{
Dossier: \\ Lèxic i edició de textos catalans antics de medicina, ciència i tècnica
}

\author{
Lluís Cifuentes i Comamala \\ Universitat de Barcelona \\ lluiscifuentes@ub.edu \\ https://orcid.org/OOOO-OOOI-79I2-9859
}

Received 26/04/20I7; accepted o3/o6/20I7

DOI: https://doi.org/IO.7203/MCLM.4.IO6OI

Dossier: Lexicon and the editing of early Catalan texts on medicine, science and technology

Abstract

An introduction to the collection of articles that follow on this issue, on the subject mentioned in this title.

\section{KEYWORDS}

Early Catalan texts, medicine, veterinary medicine, agriculture, vernacularization, translations, medieval manuscripts, rare books, dictionnaries, edition, lexicon

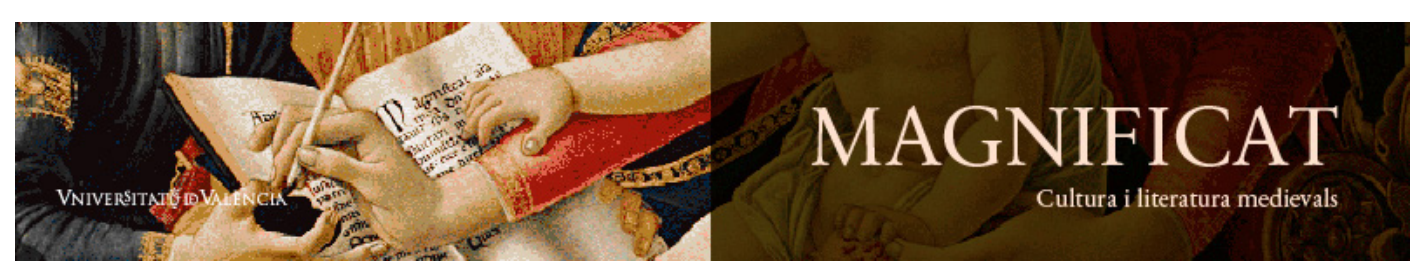

Magnificat Cultura i Literatura Medievals 4, 20I7, 43-49. http://ojs.uv.es/index.php/MCLM 
RESUM

Introducció al recull d'articles que segueixen en aquest número, sobre el tema esmentat en el títol.

PARAULES CLAU

Textos catalans antics, medicina, veterinària, agricultura, vernacularització, traduccions, manuscrits medievals, impresos antics, diccionaris, edició, lèxic

Lluís Cifuentes i Comamala. 20I7. 'Dossier: Lèxic i edició de textos catalans antics de medicina, ciència i tècnica', Magnificat Cultura i Literatura Medievals, 4: 43-49

(c) BY

Aquest dossier forma part de les iniciatives del projecte de recerca "Ciència vernacla a la Corona d’Aragó i al seu context romànic, segles XIII-XVI” (MINECO FFI20I4-53O5O-C5-3-P, 2OI5-2OI8), de l'equip del qual formen part Lluís Cifuentes, Antònia Carré i Raimon Sebastian. Així mateix, alguns autors formen part del grup de recerca consolidat per la Generalitat de Catalunya "Cultura i literatura a la Baixa Edat Mitjana" (SGR2or4-II9) i de la xarxa temàtica "Llengua i ciència” (MINECO FFI2Or5-68705-REDT), i estan vinculats al Centre de Documentació Ramon Llull (CDRL), a l'Institut de Recerca en Cultures Medievals (IRCVM), tots dos de la Universitat de Barcelona, a l'Institut d'Estudis Catalans (IEC) i a la Societat Castellonenca de Cultura (SCC).

\section{TAULA DE CONTINGUTS}

I Presentació del dossier - 45

${ }_{2}$ Obres citades $-{ }_{4} 8$ 


\section{ə*⿻丷木}

\section{Presentació del dossier}

L períodes medieval i modern, atreuen cada vegada més l'interès dels investigadors. El seu prolongat abandonament (més per part dels historiadors de la ciència que dels filòlegs) no evidencia altra cosa que les dificultats que presenta el seu estudi i edició: obres i traduccions anònimes o de mal identificar, còpies fragmentàries, pocs testimonis conservats, molts testimonis dels originals de les traduccions (sovint sense editar ni estudiar), versions manipulades, fonts poc conegudes, terminologia tècnica en plena construcció, metodologies inadequades en molta de la bibliografia existent, si n’hi ha, etc. Aquests són només alguns dels problemes que són el pa de cada dia dels especialistes; uns especialistes que han hagut d'aprendre que una formació interdisciplinària és absolutament imprescindible per a afrontar amb garanties l'estudi i l'edició d'aquestes obres. Les aportacions que integren aquest dossier volen ser representatives d'alguns d'aquests problemes i dels enfocaments i mètodes actuals a l'hora d'estudiar i editar aquestes obres.

Aquestes aportacions s’inscriuen en l'estudi de dos processos cabdals de la història cultural de l'Occident europeu medieval i modern, que van tenir, com no podia ser d'altra manera, una clara manifestació als Països Catalans. D’una banda, l'ús innovador de les llengües vulgars per a la plasmació escrita dels actes quotidians, l'entreteniment, la creació literària i l'accés al saber, que era conseqüència de l'eclosió, a partir del segle XIII, d'una societat urbana, desapareguda des del final de l'Antiguitat, i del reconeixement del valor del saber i la cultura per a la promoció de l’individu (Alberni-Badia-Cabré 2OIO; Alberni et al. 20I2; Badia-Martí 20I3; Badia et al. 2OI6). D’altra banda, l'esforç per fixar i difondre el lèxic especialitzat, amb l'elaboració de repertoris i diccionaris de diversa mena a l'entorn llatinista de la universitat medieval, però també des de l'àmbit extrauniversitari utilitzador del vulgar (Gutiérrez Rodilla, 20Oz); un esforç que la impremta va impulsar i propagar de manera abans impensable (Colón-Soberanas I99I).

Als darrers segles medievals, la comunitat catalana, dotada d'una cort que emprava la llengua vulgar i amb ella difonia models de comportament, es va incorporar ben d'hora al moviment cultural conegut com vernacularització del saber, i va impulsar la traducció i la redacció d’obres de medicina, ciència i tècnica en català (Cifuentes 2006). D'entre els articles que segueixen, els d'Antònia Carré, Lluís Gimeno Betí i Ramon Sebastian fan referència a algunes obres i traduccions d’aquestes temàtiques: de medicina, de veterinària (menescalia) i d'agricultura.

En el procés de vernacularització l'esforç terminològic és evident, i la difusió del lèxic tècnic és un excel-lent indici de la influència sociocultural que va tenir. La creació de terminologia especialitzada es va fer sobretot pel canal de les traduccions, que traslladaven al català una part del valorat saber universitari; un saber universitari que funcionava en llatí, i per això, deixant de banda excepcions, va ser sobretot el llatí la font de la nova terminologia catalana. Paral-lelament, projectes com l'Art general de Ramon Llull proposaven noves vies d'accés al saber “vernacles”, és a dir, concebudes des de fora de la universitat i per als extrauniversitaris, i generaven necessitats terminològiques pròpies (Badia-Santanach-Soler 20I6).

La universitat medieval va fomentar la creació de recursos lexicogràfics que els traductors catalans medievals van poder emprar, molt útilment classificats i descrits per Gutiérrez Rodilla (20O7). El lèxic, doncs, pot ser un indici per a la identifcació de les eines emprades pels traductors, que no solen citar, com demostra Raimon Sebastian en analitzar la traducció de Ferrer Saiol 
del tractat d'agricultura de Pal-ladi, a la qual va dedicar la tesi doctoral (Sebastian 2OI4) i altres aportacions (Sebastian 2015; Sebastian 2OI6), i que editarà pròximament. Recursos especialitzats que eren habituals entre els apotecaris, i que Saiol podia haver conegut a casa de la seva muller, vídua d'un apotecari, o al seu entorn, com el repertori de simples d'Ibn Wāfid (el Ps.-Serapió de la tradició llatina) o la Clavis sanationis de Simó de Gènova, però també les eines gramaticals que eren conegudes entre els notaris, aporten dades per a interpretar la traducció i les al·lusions genèriques, fins ara misterioses, als instruments emprats pel traductor que hi ha a l'important pròleg que conté.

Però va ser sobretot a partir de finals del segle XV i durant l'època moderna que, gràcies a la impremta, aquest tipus de recursos lexicogràfics va tenir una difusió més gran. Poden citar-se, principalment, el Vocabulari català-alemany de l'any I5O2 (editat a Lamarca et al. 20O7), pensat per a la conversa entre mercaders, que es va traduir d'un original italià; el Vocabularius d'Antonio de Nebrija, amb una notable insistència en la medicina, traduït del llatí i el castellà i ampliat a partir de I5O7, que quatre anys més tard es va traduir al francès a partir del català (Soberanas 1977); o el Gazophylacium catalano-latinum de Joan Lacavalleria, traduït del francès l'any i696, amb una gran quantitat de lèxic científic i tècnic. Tots ells són testimonis d’una època en la qual la fixació de la terminologia tècnica va tenir, amb aquests recursos, unes possibilitats d'èxit encara més grans que abans (l'important diccionari de Castelli I598, una eina bàsica per a la recerca sobre el vocabulari de la medicina galènica, és un exemple destacat d'aquestes actituds modernes). Però, en darrera instància, es tracta d'unes iniciatives que manifesten una continuïtat, i no una ruptura, com la fâcil assumpció de la propaganda antimedieval dels renaixentistes encara massa vegades fa pensar en aquest i en altres temes. Així ho demostra l'aportació de Pere Montalat, justament sobre l’obra de Lacavalleria, a la qual ja ha dedicat alguns articles anteriors (Montalat 2OI5a; Montalat 2OI5b).

L’anàlisi del lèxic de les obres i les traduccions és també d'un gran valor per a la datació i la localització dels testimonis manuscrits antics, sovint anònims i gens fâcils d'estudiar i editar. El compendi de menescalia inèdit de la Societat Castellonenca de Cultura, presentat aquí per primera vegada per Lluís Gimeno Betí, n’és un bon exemple. En aquest manuscrit, copiat molt probablement per a ús d'un mercader de Morella de mitjan segle XIV, pot veure's també com l'ús del lèxic tècnic reprodueix la difusió social de la menescalia força més enllà dels mateixos menescals en aquella societat tan dependent dels equins (Cifuentes-Ferragud-García Ballester i999; Ferragud 2009); una difusió que l'autor ja havia explorat en la medicina humana (Gimeno 20I4).

L’edició crítica de les obres de medicina, ciència i tècnica ha aportat i aporta un devessall de vocabulari especialitzat als diccionaris històrics de la llengua catalana (Cifuentes 2OI2) i són l’ocasió per a fer balanç i corregir o aprofundir en les definicions. Antònia Carré, per ser autora d’un bon nombre de les edicions crítiques més recents (Carré 2000; Carré 2004; Carré 2OI7; Carré-Cifuentes 2OI7), ho coneix bé. Al seu article, posa de manifest fins a quin punt els errors editorials han esmunyit terminologia espúria en els diccionaris històrics catalans (en particular, el DCVB i els de Coromines i Faraudo). Aquests errors tenen l'origen en situacions en les quals es tenia un coneixement incipient i incomplet tant del fenomen de la vernacularització del saber com de les obres i el seu vocabulari, però també de la ciència llatina, i no es disposava dels recursos d'informació actuals.

Els articles que formen part d'aquest dossier mostren, en darrera instància, que el vocabulari especialitzat no és un testimoni mut del passat sinó que, ben al contari, és un indicador de gran importància de l'interès per les diverses branques del saber i de la seva penetració social, que és, al capdavall, el que impulsa la creació terminològica. L’equip de recerca Sciència.cat assumeix aquests pressupòsits i per això té molt en compte el vocabulari tècnic en les edicions que publica $\mathrm{i}$ en la base de dades que manté a la xarxa (Sciència.cat DB). El lloc web (http://www.sciencia.cat) conté igualment informació suplementària sobre alguns dels temes tractats en aquests articles: la 
vernacularització de la medicina en català, la menescalia, síntesis sobre algunes traduccions i obres originals en català, o la figura i l'aportació de Lluís Faraudo de Saint-Germain.

Finalment, volem fer constar que el tema dels articles d'aquest dossier va ser objecte d'una primera presentació a la XIV Trobada d'Història de la Ciència i de la Tècnica, de la Societat Catalana d'Història de la Ciència i de la Tècnica, filial de l'IEC (Castelló de la Plana, 27-29 d'octubre de 20I6), i a la XIII Jornada de la Societat Catalana de Terminologia, també filial de l'IEC (Barcelona, 30 de novembre de 20I6). Agraïm als responsables d'aquestes trobades que acollissin amb tant d'interès aquesta temàtica i aquestes aportacions, que ara prenen forma definitiva aquí, i fem constar també el nostre agraïment a Rosanna Cantavella per la seva predisposició i entusiasme. 


\section{${ }_{2}$ Obres citades}

Alberni, Anna; Badia, Lola; Cabré, Lluís (ed.). 20ıo. Translatar i transferir: la transmissió dels textos i el saber (1200-1500) (Santa Coloma de Queralt: Obrador Edèndum; Tarragona: Universitat Rovira i Virgili)

Alberni, Anna; Badia, Lola; Cifuentes, Lluís; Fidora, Alexander (ed.). 20I2. El saber i les llengües vernacles a l'època de Llull i Eiximenis: estudis ICREA sobre vernacularització / Knowledge and Vernacular Languages in the Age of Llull and Eiximenis: ICREA Studies on Vernacularization (Barcelona: Publicacions de l'Abadia de Montserrat)

Badia, Lola; Cifuentes, Lluís; Martí, Sadurní; Pujol, Josep (ed.). 20I6. Els manuscrits, el saber i les lletres a la Corona d'Aragó, 1250-150o (Barcelona: Publicacions de l'Abadia de Montserrat)

Badia, Lola; Martí, Sadurní. 20I3. 'Edat Mitjana i literatura', in Història de la literatura catalana, ed. by Àlex Broch (Barcelona: Enciclopèdia Catalana; Barcino; Ajuntament de Barcelona), III: Literatura medieval (I): dels orígens al segle XIV, ed. by Lola Badia, I7-46

Badia, Lola; Santanach, Joan; Soler, Albert. 20I6. Ramon Llull as a Vernacular Writer: Communicating a New Kind of Knowledge (London: Tamesis)

Carré, Antònia (ed.). 200o. Hipòcrates Aforismes: traducció catalana medieval, amb la col-laboració de Francesca Llorens (Barcelona: Curial Edicions Catalanes; Publicacions de l'Abadia de Montserrat)

Carré, Antònia (ed.). 2004. Girolamo Manfredi Quesits o perquens (regiment de sanitat i tractat de fisiognomonia), Els Nostres Clàssics, B 25 (Barcelona: Barcino)

Carré, Antònia (ed.). 20I7. Arnau de Vilanova Regiment de sanitat per al rei d'Aragó - Aforismes de la memòria (Barcelona: Universitat de Barcelona)

Carré, Antònia; Cifuentes, Lluís (ed.). 20I7. La traducció catalana medieval del 'Lilium medicine' de Bernat de Gordon: estudi i edició del fragment conservat (llibre VII, Antidotari), Papers of the Medieval Hispanic Research Seminar, 76 (London: Queen Mary University of London, Medieval Hispanic Research Seminar)

Castelli, Bartolomeo. I598. Lexicon medicum Graecolatinum Bartholomaei Castelli Messanensis studio ex Hippocrate et Galeno desumptum (Messina: Typis Petri Breae) < $\underline{\text { https: / / tinyurl.com/ }}$ ybyys6fy $>$ [accessed 24-O7-2OI7] [Amb moltes edicions posteriors acrescudes, la darrera el I795]

Cifuentes, Lluís. 2006. La ciència en català a l'Edat Mitjana i el Renaixement, 2nd ed., Col-lecció Blaquerna, 3 (Barcelona: Universitat de Barcelona; Palma: Universitat de les Illes Balears)

Cifuentes, Lluís. 20I2. 'Hacia un nuevo Vocabulario del catalán técnico medieval', in Léxico de la ciencia: tradición y modernidad, ed. by Graça Rio-Torto (München: LINCOM GmbH), pp. 33-56

Cifuentes, Lluís; Ferragud, Carmel; García Ballester, Luis. 1999. 'Els menescals i l'art de la menescalia a la Corona d'Aragó durant la Baixa Edat Mitjana', in Història de la ramaderia i la veterinària als Paüsos Catalans: IV Col-loqui d'història agrària (maig del 1997), actes (Barcelona: Universitat de Barcelona; Centre d'Estudis d'Història Rural), pp. 75-98 $<$ https://tinyurl.com/ yggvexdc>

Colón Domènech, Germà; Soberanas, Amadeu J. I99I. Panorama de la lexicografia catalana: de les glosses medievals a Pompeu Fabra, 2nd ed. (Barcelona: Enciclopèdia Catalana) 
Colón Domènech Germà (ed.). 2007. Lluís Faraudo de Saint-Germain Vocabulari de la llengua catalana medieval (Barcelona: Institut d'Estudis Catalans) $<$ http://www.iec.cat/faraudo $>$ [accessed 24-O7-2OI7]

Coromines, Joan. I980-200I. Diccionari etimològic i complementari de la llengua catalana, Io vols, amb la col-laboració de Joseph Gulsoy i Max Cahner, i l'auxili tècnic de Carles Duarte i Àngel Satué (Barcelona: Curial; Caixa de Pensions 'la Caixa')

DCVB: Alcover, Antoni M.; Moll, Francesc de B. I964-I969. Diccionari català-valencià-balear: inventari lexicogràfic i etimològic de la llengua catalana en totes les seves formes literàries $i$ dialectals, recollides dels documents i textos antics i moderns, i del parlar vivent..., obra iniciada per Antoni M. Alcover; redactat per Antoni M. Alcover i Francesc de B. Moll, 2nd ed., Io vols (Palma: Moll) < $\underline{\text { http://dcvb.iecat.net }}>$ [accessed 24-O7-2OI7]

Ferragud Domingo, Carmel. 20o9. La cura dels animals: menescals i menescalia a la València medieval (Catarroja: Afers)

Gimeno Betí, Lluís. 20I4. 'El lèxic mèdic català durant la baixa Edat Mitjana, entre la terminologia popular i la culta; materials per al seu estudi: el cas de l'Speculum al foder', Estudis Romànics, 36 : 343-372 $<\underline{\text { http://tinyurl.com/mzkuuov }><D O I ~ I O .2436 / 20.250 O . O I . I 55 ~}>$

Gutiérrez Rodilla, Bertha M. ${ }^{\mathrm{a}}$ 2007. La esforzada reelaboración del saber: repertorios médicos de interés lexicográfico anteriores a la imprenta (San Millán de la Cogolla: CiLengua, Instituto de Historia de la Lengua)

Lamarca, Dolors, et al. (ed.). 2007. Vocabulari català-alemany imprès a Perpinyà per Joan Rosembach el 1502 / Vocabular Katalanisch-Deutsch gedruckt in Perpignan von Joan Rosembach 1502, 2 vols (Barcelona: Biblioteca de Catalunya; Institut Ramon Llull)

Montalat, Pere. 20I5a. 'La font francesa del Gazophylacium catalano-latinum de Joan Lacavalleria', Llengua \& Literatura, 25: 7-27 <http://tinyurl.com/ya04qtyy $><$ DOI IO.2436/20.25O2.0I.7I $>$

Montalat, Pere. 20I5b. 'Contribució a l'estudi del lèxic del Gazophylacium catalano-latinum', Estudis Romànics, 37: 373-384 <

Sebastian, Raimon. 20I4. 'Ferrer Saiol, traductor de Pal-ladi' (unpublished doctoral thesis, Universitat de Barcelona) $<$ http://hdl.handle.net/Io803/283132 $>$

Sebastian, Raimon. 20I5. 'Las fuentes latinas de Ferrer Saiol como traductor de Paladio', in Humanismo y pervivencia del mundo clásico, V:homenaje al profesor Juan Gil, ed. by José María Maestre Maestre et al. (Alcañiz: Instituto de Estudios Humanísticos), II: IO55-IO65

Sebastian, Raimon (ed.). 2oI6. Pal-ladi Rutili Taure Emilià, Tractat d'agricultura, Col-lecció Bernat Metge, 4I4 / Escriptors Llatins (Barcelona: Fundació Bernat Metge), I: Llibres I-II

Sciència.cat. La ciència en la cultura catalana a l'Edat Mitjana i el Renaixement, ed. by Lluís Cifuentes and Antònia Carré (Barcelona: Centre de Documentació Ramon Llull de la Universitat de Barcelona) <http://www.sciencia.cat $>$ [accessed 24-O7-2OI7]

Sciència.cat DB. Base de dades de la ciència i la tècnica en català a l'Edat Mitjana i el Renaixement, ed. by Lluís Cifuentes (Barcelona: Centre de Documentació Ramon Llull de la Universitat de

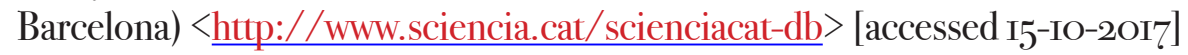

Soberanas, Amadeu-J. 1977. 'Les edicions catalanes del diccionari de Nebrija', in Actes del quart Col.loqui Internacional de Llengua i Literatura Catalanes, Basilea 1976, ed. by Germà Colón (Barcelona: Publicacions de l’Abadia de Montserrat), pp. I4I-2O3 